\title{
Hubungan Lingkar Pinggang dan Lingkar Panggul dengan Tekanan Darah pada Pasien Program Pengelolaan Penyakit Kronis (Prolanis)
}

\author{
Sumardiyono $^{1}$, Eti Poncorini Pamungkasari ${ }^{1}$, Anton Giri Mahendra², Oki \\ Saraswati Utomo ${ }^{2}$, Devita Mahajana ${ }^{2}$, Wakhid Ryan Cahyadi², Mila Ulfia ${ }^{2}$ \\ 1. Bagian Ilmu Kesehatan Masyarakat Fakultas Kedokteran, Universitas Sebelas Maret Surakarta \\ 2. Program Studi Profesi Dokter Fakultas Kedokteran, Universitas Sebelas Maret Surakarta
}

Korespondensi: sumardiyono_uns@yahoo.com

\begin{abstract}
ABSTRAK
Pendahuluan:Obesitas adalah suatu keadaan terjadi akumulasi jumlah lemak dalam tubuh yang berlebihan, yang menjadi faktor resiko penyakit kardiovaskuler. Obesitas dapat diukur menggunakan metode antropometri pengukuran lingkar pinggang dan lingkar panggul. Penelitian ini bertujuan untuk mencari hubungan antara ukuran lingkar pinggang dan lingkar panggul terhadap tekanan darah pada pasien peserta prolanis di wilayah kerja Puskesmas Kedawung I, Kabupaten Sragen.

Metode:Penelitian ini merupakan penelitian observasional analitik dengan menggunakan rancangan cross sectional. Subjek penelitian merupakan pasien peserta prolanis dengan riwayat hipertensi di wilayah Puskesmas Kedawung I Sragen pada bulan Juli 2017. Pengambilan sampel dilakukan dengan carasimple random sampling berjumlah 60 sampel.

Hasil :Ada hubungan signifikan antara lingkar pinggang terhadap tekanan darah sistolik dan diastolik namun memiliki kekuatan lemah ( $r=0,304 ; p=0,018$ dan $r=0,337 ; p=0,008)$. Ada hubungan signifikan antara lingkar panggul terhadap tekanan darah sistolik dan diastolik namun memilki kekuatan lemah ( $r=0,263 ; p=0,042$ dan $r=0,306 ; p=0,017)$.

Kesimpulan: semakin besar ukuran lingkar pinggang dan lingkar panggul maka semakin tinggi risiko peningkatan tekanan darah pada pasien peserta prolanis.
\end{abstract}

Kata Kunci: Lingkar Pinggang, Lingkar Panggul, Tekanan Darah, Prolanis.

\begin{abstract}
Introduction: Obesity is a state of excessive accumulation of fat in the body, which is a risk factor for cardiovascular disease. Obesity can be measured using anthropometric methods measuring waist circumference and hip circumference. This study aims to find the relationship between the size of waist circumference and hip circumference to blood pressure in prolanis participants in the working area of Kedawung I Public Health Center, Sragen Regency.

Method: This study was an observational analytic study using a cross sectional design. The subjects were prolanis participant patient with a history of hypertension in the Kedawung I Community Health Center in Sragen in July 2017. Sampling was done by simple random sampling. The number of subject were 60 persons.

Results: There were significant relationship between waist circumference and systolic/ diastolic blood pressure with weak strength $(r=0.304 ; p=0.018$ and $r=0.337 ; p=$ 0.008 ) and significant relationship between hip circumference with systolic/diastolic blood pressure with weak strength $(r=0.263 ; p=0.042$ and $r=0.306 ; p=0.017)$.

Conclusion: the increasing size of waist and hip circumference may increase blood pressure in prolanis participants.
\end{abstract}


Keywords: Waist circumference, Hip circumference, Blood Pressure, Prolanis.

\section{PENDAHULUAN}

Obesitas adalah suatu keadaan pada manusia, yaitu terjadinya akumulasi jumlah lemak dalam tubuh yang berlebihan. Pada tahun 2014, sekitar 600 juta manusia di dunia menderita obesitas ${ }^{1}$. Dahulu, obesitas dianggap sebagai masalah pada penduduk negara maju. Namun akhir-akhir ini, masalah ini semakin merambah ke penduduk pada negara berkembang, khususnya negara di Asia Tenggara ${ }^{2}$. Angka kejadian obesitas di Indonesia pada tahun 2008 mencapai 2,6\% pada pria, dan $6,9 \%$ pada wanita dengan populasi pendapatan menengah ke bawah ${ }^{3}$.

Prevalensi kematian yang disebabkan oleh obesitas masih belum jelas, bervariasi antara $5-13 \% \%^{4}$. Obesitas dapat meningkatkan risiko terkena penyakit seperti hipertensi, diabetes melitus, dan penyakit kardiovaskuler lain $^{5}$. Badan Penelitian dan Pengembangan Kesehatan tahun 2013 mencatat prevalensi hipertensi di Indonesia pada penduduk berusia lebih dari 18 tahun berjumlah $25,8 \%$, dan kejadian hipertensi pada wanita lebih tinggi dibanding pria $^{6}$. Di Jawa Tengah, Badan Penelitian dan Pengembangan Kesehatan mencatat terdapat $26,4 \%$ populasi yang mengalami hipertensi pada individu berusia lebih dari 18 tahun. Prevalensi obesitas sentral pada individu berusia dewasa tercatat $22,2 \%$, dengan rincian $39,4 \%$ perempuan dan $9,7 \%$ laki-laki.

Seiring dengan bertambahnya usia, kebutuhan zat gizi karbohidrat dan lemak umumnya lebih rendah karena adanya penurunan metabolisme basal. Proses metabolisme yang menurun pada usia lanjut akan beresiko mengakibatkan kegemukan karena terjadi penurunan aktivitas fisik, maka kalori yang berlebih akan diubah menjadi lemak sehingga mengakibatkan kegemukan. Proses menua menyebabkan proporsi lemak dan otot dalam tubuh berubah menjadi semakin tua dan melemah sehingga menyebabkan kegemukan (obesitas). Puncak kenaikan berat badan pada wanita terjadi pada usia 55-65 tahun dan pria pada usia 34-54 tahun 7 .

Salah satu metode deteksi individu obesitas dengan hipertensi adalah dengan menggunakan pengukuran antropometri. Pengukuran antropometri yang dilakukan antara lain pengukuran massa badan, lingkar pinggang, dan lingkar panggul ${ }^{8}$. Indeks Massa Tubuh (IMT) adalah metode yang sering digunakan untuk mendeteksi individu dengan obesitas. Selain IMT, pengukuran lingkar panggul dan pinggang dapat digunakan untuk mendeteksi individu obesitas dengan hipertensi. Riset membuktikan bahwa rasio lingkar pinggang dan panggul adalah indikator yang lebih baik daripada IMT untuk mendeteksi hipertensi pada individu9 .

Pasien program pengelolaan penyakit kronis perlu dijaga supaya penyakitnya dapat terkontrol. Berdasar hal tersebut maka penelitian mengenai hubungan lingkar pinggang dan lingkar panggul dengan tekanan darah pada pasien program pengelolaan penyakit kronis di Puskesmas Kedawung I, Kabupaten Sragen perlu dilakukan.

\section{METODE}

Penelitian ini merupakan penelitian observasional analitik dengan pendekatan cross sectional yang dilakukan di Puskesmas Kedawung I pada Juli 2017.Teknik sampling yang digunakan pada penelitian ini adalah consecutive sampling, yaitu salah satu dari sampling tipe non-probabilitas. Consecutive sampling berarti seluruh populasi dipilih 
untuk dijadikan responden, yang memenuhi kriteria inklusi dan eksklusi, sampai didapatkan sejumlah subjekyang dibutuhkan. Kriteria inklusi: pasien prolanis Puskesmas Kedawung I Sragen, bersedia menjadi subjek, datang pada saat pengambilan data. Kriteria eksklusi: menolak untuk menjadi subjek penelitian. Jumlah subjek ditentukan menggunakan kriteria rule of thumb. Jumlah variabel ada 3, sehingga jumlah subjek minimal 45 orang, namun dalam penelitian ini digunakan subjek berjumlah 60 orang.

Variabel bebas yang diteliti adalah lingkar pinggang dan lingkar panggul. Variabel ini diukur menggunakan metline dengan satuan sentimeter. Pengukuran lingkar pinggang dilakukan pada saat ekspirasi, dengan posisi tubuh berdiri tegak dengan pakaian ditanggalkan, namun karena masalah etika, maka dilakukan pengukuran dengan responten tetap memakai baju yang hasilnya dikurangi tebal baju. Pita di taruh diantara crista iliaca dan costae XII, pada lingkaran yang terkecil. Pengukuran lingkar pangguldiukur pada lingkar maksimal dari regio gluteus dan di atas symphisis ossis pubis. Variabel terikat yang diteliti adalah tekanan darah. Variabel ini diukur menggunakan sphygmomanometer dengan satuan milimeter raksa $(\mathrm{mmHg})$. Subjek didudukkan dengan nyaman, dengan lengan kanan dalam keadaan relaksasi minimal 5 menit. Tekanan darah yang dimaksud adalah tekanan darah sistolik dan diastolik.

Teknik analisis data yang digunakan dalam penelitian ini adalah uji korelasi Spearman dengan signifikansi 5\%. Perhitungan menggunakan software SPSS versi 22.

\section{HASIL}

Pengambilan data penelitian dilakukan pada pasien Prolanis Puskesmas Kedawung I Sragen. Pelaksanaan pengambilan data pada bulanJuli 2017. Waktu pengambilan data dilakukan pada pagi hari sebelum pelaksanaan senam prolanis.Pengambilan sampel dilakukan secara konsekutif sampling, peneliti mengambil sampel yang memenuhi kriteria yang telah ditentukan hingga didapatkan sejumlah sampel minimal. Jumlah responden atau subjek penelitian sebanyak 60 orang. Deskripsi responden berdasarkan jenis kelamin tersaji pada tabel 1 .

Tabel 1. Deskripsi responden berdasarkan jenis kelamin

\begin{tabular}{lrr}
\hline Jenis Kelamin & Frekuensi & Persentase \\
\hline Pria & 18 & $30 \%$ \\
Wanita & 42 & $70 \%$ \\
\hline Total & 60 & $100 \%$ \\
\hline
\end{tabular}

Dari 60 orang responden, lebih banyak wanita dibanding pria. Selanjutnya dilakukan pengukuran lingkar pinggang, lingkar panggul, tekanan darah sistolik, dan tekanan darah diastolik pada masing-masing responden. Selanjutnya hubungan antar variabel digunakan uji korelasi Spearman.

Hubungan antar variabel yang diujimasing-masing hubungan antara lingkar pinggang dengan tekanan darah sistolik, hubungan lingkar panggul dengan tekanan darah diastolik, hubungan lingkar panggul dengan tekanan darah sistolik, dan hubungan lingkar panggul dengan tekanan darah diastolik. Hasil uji korelasi antar variabel tersaji pada tabel 2 .

Tabel 2. Uji korelasi data Spearman.

\begin{tabular}{llll}
\hline Variabel & $\begin{array}{l}\text { Tekanan darah } \\
\text { sistolik }\end{array}$ & $\begin{array}{l}\text { Tekanan } \\
\text { diastolik }\end{array}$ & darah \\
\hline Lingkar & $\mathrm{r}=0,304$ & $\mathrm{r}=0,337$ \\
pinggang & $\mathrm{p}=0,018$ & $\mathrm{p}=0,008$ \\
Lingkar & $\mathrm{r}=0,263$ & $\mathrm{r}=0,306$ \\
panggul & $\mathrm{p}=0,042$ & $\mathrm{p}=0,017$ \\
\hline
\end{tabular}

Dari hasil uji korelasi Spearman, maka didapatkan hasil yang menyatakan ada hubungan yang signifikan antara kedua variabel bebasterhadap kedua variabel terikat $(\mathrm{p}<0,05)$. Hubungan antara kedua variabel bernilai positif $(\mathrm{r}=$ positif $)$ menunjukkan bahwa peningkatan nilai variabel lingkar 
pinggang dan lingkar panggul, maka diikuti peningkatan variabel tekanan darah sistolik dan diastolik.

\section{PEMBAHASAN}

Hubungan antara kedua variabel masingmasing berkekuatan lemah karena nilai $r$ terletak antara 0,2 dan 0,4. Masing-masing kekuatan hubungan adalah lingkar pinggang dengan tekanan darah sistolik $(\mathrm{r}=0,304)$, lingkar pinggang dan tekanan darah diastolik $(\mathrm{r}=0,337)$, lingkar panggul dan tekanan darah sistolik $(r=0,236)$, dan lingkar panggul dan tekanan darah diastolik ( $\mathrm{r}=0,306)$; namun demikian semuanya signifikan $(\mathrm{p}<0,05)$. Dengan demikian hasil uji menunjukkan hubungan positif antara besar ukuran lingkar pinggang dan lingkar panggul terhadap tekanan darah.

Hasil penelitian ini menunjukkan bahwa lingkar pinggang dan lingkar panggul adalah salah satu pemeriksaan yang hasilnya dapat dijadikan interpretasi individu yang mengalami obesitas atau tidak $^{10}$. Individu yang mempunyai lingkar pinggang dan lingkar panggul tinggi secara otomatis mempunyai distribusi lemak yang lebih tinggi pada daerah abdominal ${ }^{11}$. Distribusi lemak yang tidak merata pada daerah abdominal secara tidak langsung menyebabkan kadar trigliserid pada peredaran darah semakin tinggi, dan akan berpengaruh pada tinggi rendahnya tekanan darah ${ }^{12}$.

Ada beberapa hal yang dapat memengaruhi hasil dari penelitian ini yaitu ukuran berat badan dan tinggi badan. Berat badan dan tinggi badan adalah komponen yang dibutuhkan untuk mengetahui Indeks MassaTubuh (IMT). Pada individu dengan IMT lebih dari $25 \mathrm{~kg} / \mathrm{m}^{2}$ diklasifikasikan sebagai individu dengan obesitas. Penduduk Indonesia memiliki risiko hipertensi pada individu dengan obesitas sebesar 7,64 kali dibanding yang ideal. Semakin tinggi IMT, maka tekanan darah akan semakin meningkat ${ }^{13}$.

Dalam penelitian ini peneliti memiliki beberapa keterbatasan, antara lain beberapa variabel perancu yang dapat mempengaruhi tekanan darahpada penelitian ini belum diukur. Variabel perancu tersebut antara lain kadar hormon yang memengaruhi tekanan darah seperti renin, angiotensin, dan hormon tiroid. Aktivitas hormon ini berpengaruh secara variatif pada tinggi rendahnya tekanan darah $^{14,15,16 .}$.

Variabel perancu yang lain adalah struktur gen pada responden yang memengaruhi tekanan darah yang tidak dapat diketahui. Beberapa gen seperti ATP2B1, CYP17A1, PLEKHA7 memengaruhi tekanan darah sistolik. Sementara gen ATP2B1, CACNB2, $\quad$ CSK/ULK3, SH2B3, TBX3/TBX5, dan ULK4 memengaruhi tekanan darah diastolik. Gen ATP2B1 berperan dalam hipertensi pada individu ${ }^{17}$.

Peneliti juga tidak mengukur variabel gaya hidup dari responden yang diteliti. Salah satu gaya hidup adalah asupan makanan responden yang diperoleh dari pola makan. Asupan garam pada makanan yang dikonsumsi oleh responden akan berpengaruh pada tinggi rendahnya tekanan darah. Kadar garam akan berpengaruh pada produksi hormon ouabain yang diproduksi oleh ginjal. Hormon ini akan meningkat ketika individu telah mengonsumsi garam dalam jumlah banyak. Selain hormon oubain, pompa natrium vaskular dan $\mathrm{NCX} \quad(\mathrm{Na} / \mathrm{Ca}$ exchangers) juga berperan dalam peningkatan tekanan darah ${ }^{18}$.

Selain kandungan garam, kafein dapat memengaruhi tekanan darah. Kafein akan meningkatkan kalsium intraseluler pada sel endotelial, menyebabkan produksi nitrit oksida meningkat. Nitrit oksida akan berdifusi ke sel otot polos yang ada di sekitar pembuluh darah, menyebabkan pelebaran pembuluh darah (vasodilatasi). Selain efek vasodilatasi, reseptor adenosin yang ada pada jaringan 
vaskular akan diblokir, menyebabkan efek penyempitan pembuluh darah (vasokonstriksi). Mekanisme kafein pada tekanan darah masih belum diketahui secara pasti, namun dapat dipastikan bahwa kafein akan meningkatkan tekanan darah selama 3 jam. Jika responden mengonsumsi kafein sesaat sebelum pengambilan data, tekanan darah pada responden akan meningkat ${ }^{19,20}$.

\section{KESIMPULAN}

Semakin besar ukuran lingkar pinggang dan lingkar panggul dapat meningkatkan resiko tekanan darah pada peserta prolanis.

\section{UCAPAN TERIMA KASIH}

Penulis mengucapkan terima kasih kepada:

1. Dekan Fakultas Kedokteran UNS, yang telah menugaskan tim peneliti untuk melaksanakan penelitian.

2. Kepala Puskesmas Kedawung I Kabupaten Sragen, yang telah memberikan ijin sebagai tempat dilaksanakannya penelitian.

\section{DAFTAR PUSTAKA}

1. WHO. Global Health Observatory Data: Obesity. World Health Organization. http://www.who.int/gho/ncd/risk_factors/ obesity_text/en/ - diakses Juli 2017.

2. Prentice AM. The emerging epidemic of obesity in developing countries. Int $J$ Epidemiol 2006; 35(1):93-99.

3. WHO. World Health Organization Noncommunicable Diseases (NCD) Country Profiles. http://www.who.int /nmh/publications/ncd-profiles-2014/en/ diakses Juli 2017.

4. Zheng H, Tumin D, Qian Z. Obesity and mortality risk: new findings from Body Mass Index trajectories. Am J Epidemiol 2013; 178(11):1591-1599.
5. Ramachandran A, Snehalatha C. Rising Burden of Obesity in Asia. $J$ of Obesity. 2010. Article ID 868573

6. Badan Penelitian dan Pengembangan Kesehatan. 2014. Laporan Riset Kesehatan Dasar (Riskesdas) 2013. Jakarta: Kementrian Kesehatan Republik Indonesia.

7. Yazdani M, Rezaei S, Pahlavanzadeh S. 2010. The effectiveness of stress management training program on depression, anxiety, and stress of the nursing students.Iran J Nurs Midwifery Res 2010; 15(4):208-15.

8. Yalcin BM, Sahin EM, Yalcin E.Which anthropometric measurements is most closely related to elevated blood pressure?.Fam Pract 2005; 22(5): 541547.

9. Yusuf S, Hawken S, Ônpuu S, Bautista L, Franzosi MG, Commerford P, Lang $\mathrm{CC}$, et al. Obesity and the risk of myocardial infarction in 27000 participants from 52 countries: a casecontrol study. Lancet 2005; 366(9497): 1640-9.

10. Warren TY, Wilcox S, Dowda M, Baruth M. Independent association of waist circumference with hypertension and diabetes in African-American women, South Carolina, 2007-2009. Prev Chronic Dis 2012; 9:110170.

11. Snijder MB, Zimmet PZ, Visser M, Dekker JM, Seidell JC, Shaw JE. Independent and opposite associations of waist and hip circumferences with diabetes, hypertension and dyslipidemia: the AusDiab Study. Int J Obes 2004; 28 : 402-409.

12. Despres JP. Body fat distribution and risk of cardiovascular disease. Circulation 2012; 126: 1301-1313

13. Tesfaye F, Nawi NG, Van Minh H, Byass $\mathrm{P}$, Berhane $\mathrm{Y}$, Bonita $\mathrm{R}$, Wall S. Association between body mass index and blood pressure across three populations in 
Africa and Asia. Journal of Human Hypertension 2007; 21: 28-37

14. Richard, R. Obesity-Related Hypertension. The Ochsner Journal 2009; 9:133-136

15. Landsberg L, Aronne LJ, Beilin LJ, Burke V, Igel LI, Lloyd-Jones D, Sowers J. Obesity-Related Hypertension:

16. Danzi S and Klein I. 2003. Thyroid hormone and blood pressure regulation. Current Hypertension Reports 2003; 5(6): 513-20.

17. Levy D, Ehret GB, Rice K, Verwoert GC, Launer LJ, Dehghan A, Glazer NL, et al. 2009. Genome-wide association study of blood pressure and hypertension. Nature Genetics 2009; 41(6): 677-687.

18. Karppanen H and Mervaala E. Progress in cardiovascular diseases. Science Direct 2006; 49(2): 59-75.

19. Mesas AE, Leon-Munoz LM, RodriguezArtalejo F, Lopez-Garcia E. The effect of coffee on blood pressure and cardiovascular disease in hypertensive individuals: a systematic review and meta-analysis. Am J Clin Nutr 2011; 94 (4):1113-26.

20. Echeverri D, Montes FR, Cabrera M, Galan A, Prieto A. 2010. Caffeine's vascular mechanisms of action. Int J Vasc Med 2010; 834060 . 